\title{
Decreased Cerebral Blood Flow in Renal Transplant Recipients
}

\author{
Chisako Kamano, Yuichi Komaba, Osamu SaKayori, Yasuhiko Irno and Yasuo Katayama
}

\begin{abstract}
Objective We performed single-photon emission computed tomography (SPECT) to investigate the influence of renal transplantation on cerebral blood flow (CBF).

Patients and Methods Fifteen renal transplant recipients and twelve normal subjects underwent cerebral SPECT with $\mathrm{N}$-isopropyl- $p-\left[{ }^{123} \mathrm{I}\right]$ iodoamphetamine ( ${ }^{123} \mathrm{I}$-IMP). All transplant recipients received prednisolone and cyclosporine (CyA). Regional CBF (rCBF) was measured by defining regions of interest in the cerebral cortex, deep white matter, striatum, thalamus, and cerebellum. In transplant recipients, correlations to the mean overall cortical CBF were assessed using the interval from transplantation to measurement of SPECT, as well as the serum creatinine concentration. Moreover, to investigate the influence of $\mathrm{CyA}$ on CBF, the correlation between mean overall cortical CBF and $\mathrm{CyA}$ trough concentrations was assessed.

Results In all regions, $\mathrm{CBF}$ in renal transplant recipients was significantly lower than in normal subjects. No significant correlation was seen between serum creatinine, interval from transplantation, or $\mathrm{CyA}$ trough concentrations and mean overall cortical CBF.

Conclusion Renal transplant recipients demonstrated a decrease in CBF, that can have an associated secondary pathology. Therefore, renal transplant recipients may benefit from post-operative MRI or CT.

(Internal Medicine 41: 677-683, 2002)
\end{abstract}

Key words: cyclosporine, deformability, calcium, endothelin, SPECT (single-photon emission computed tomography)

\section{Introduction}

Renal transplantation and maintenance hemodialysis (HD) are two major strategies for treating end-stage renal disease (ESRD). Studies of cerebral blood flow (CBF) in HD patients demonstrated higher CBF levels than in normal subjects $(1,2)$, as determined by single-photon emission computed tomogra- phy (SPECT), positron emission tomography (PET), or Xenon CT (1-3). Increased CBF in HD patients is thought to result from decreased blood viscosity. Blood usually is less viscous in HD patients than in normal subjects because of anemia. Blood viscosity is an important factor in determining flow (4); the relationship between blood flow through vessels and viscosity is defined by the Hagen-Poiseuille equation. Not only is CBF in maintenance HD patients higher than in normal subjects, but also normalization of the hematocrit in HD patients by treatment with human recombinant erythropoietin (rhEPO) results in significant normalization of the increased $\operatorname{CBF}(5,6)$. In contrast to the well-characterized changes in CBF in HD patients, CBF has not been studied with respect to renal transplant recipients. We therefore compared $\mathrm{CBF}$ as measured by SPECT between renal transplant recipients and normal subjects.

\section{Materials and Methods}

\section{Subjects}

We studied 15 Japanese renal transplant recipients (4 males, 11 females) ranging in age from 29 to 51 years (mean \pm SD, $39.7 \pm 9.1$ ) and 12 normal volunteer subjects ( 6 males, 6 females; hematocrit, $41.73 \pm 9.34 \%$; systolic blood pressure/ diastolic blood pressure, $125.8 \pm 12.3 / 75.8 \pm 9.0 \mathrm{mmHg}$ ) of similar age ( 24 to 59 years; mean \pm SD, $46.5 \pm 11.1$ years). Full informed consent was obtained from both the recipients and normal subjects before the initiation of the study. Serum creatinine concentrations in the recipients was $2.1 \pm 1.2 \mathrm{mg} / \mathrm{dl}$ (mean \pm SD). Fourteen renal transplant recipients had hypertension and were maintained on oral antihypertensive agents. Recipients with diabetes mellitus were excluded. Blood pressure was well controlled in all recipients. Tables 1 and 2 summarize characteristics of the recipients, all of whom were receiving immunosuppressive agents.

\section{SPECT imaging and measurement}

Recipients and normal subjects underwent SPECT in a resting state. Their ears were not plugged, but their eyes were closed. The method described by Iida et al (7) was used to measure regional (r) CBF. The SPECT scanner was a Headtome-SET080 (Shimadzu, Kyoto), which has a ring col- 


\section{KAMANO et al}

Table 1. Renal Transplant Recipients Profiles

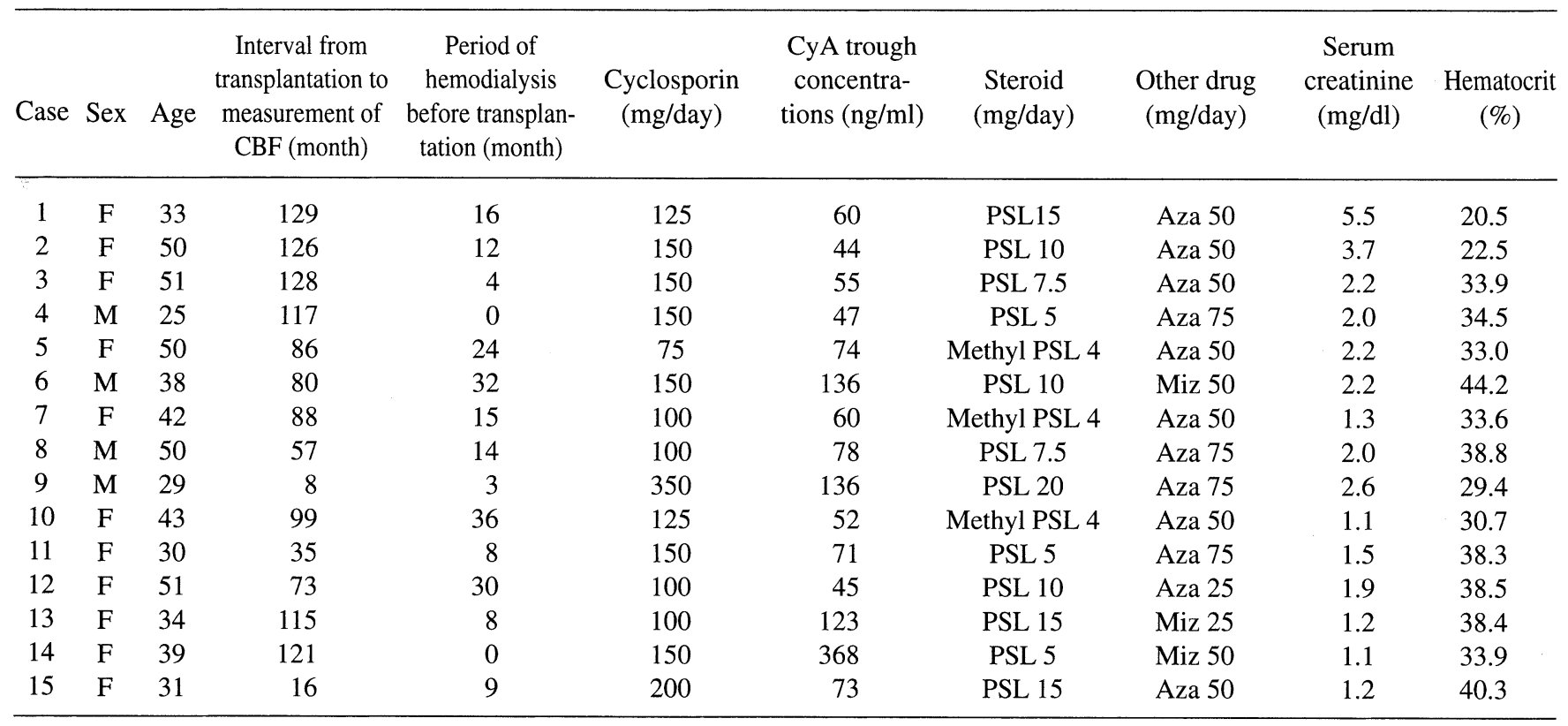

CyA: Cyclosporin, PSL: Prednisolone, Aza: Azathioprine, Miz: Mizoribine.

Table 2. Renal Transplant Recipients Profiles

\begin{tabular}{|c|c|c|c|c|c|c|}
\hline \multirow{2}{*}{ Case } & \multirow{2}{*}{ Hypertension } & \multirow{2}{*}{$\begin{array}{c}\text { Blood pressure } \\
\text { systolic/diastolic } \\
(\mathrm{mmHg})\end{array}$} & \multicolumn{4}{|c|}{ Antihypertensive drugs } \\
\hline & & & Calcium blocker & ACE inhibitor & $\alpha$ blocker & $\beta$ blocker \\
\hline 1 & + & $140 / 80$ & + & - & + & + \\
\hline 2 & + & $170 / 100$ & + & - & + & - \\
\hline 3 & + & $146 / 96$ & + & + & + & - \\
\hline 4 & + & $120 / 70$ & - & - & + & - \\
\hline 5 & + & $130 / 80$ & + & - & - & - \\
\hline 6 & + & $140 / 90$ & + & + & - & + \\
\hline 7 & + & $150 / 90$ & + & - & - & - \\
\hline 8 & + & $110 / 60$ & - & + & - & - \\
\hline 9 & + & $160 / 90$ & + & - & + & - \\
\hline 10 & + & $130 / 80$ & + & - & + & - \\
\hline 11 & + & $136 / 80$ & - & - & + & - \\
\hline 12 & + & $150 / 80$ & + & - & + & + \\
\hline 13 & + & $130 / 80$ & + & - & - & - \\
\hline 14 & + & $130 / 70$ & - & - & + & + \\
\hline 15 & - & $120 / 80$ & - & - & - & - \\
\hline
\end{tabular}

limator consisting of 96 rectangular NaI detectors. Spatial resolution at the center of view was $8.5 \mathrm{~mm}$ in full width at halfmaximum activity. Slice thickness was $5 \mathrm{~mm}$. As a tracer, 222 $\mathrm{MBq}$ of $\mathrm{N}$-isopropyl-p-[ $\left.{ }^{123} \mathrm{I}\right]$ iodoamphetamine ( ${ }^{123} \mathrm{I}$-IMP) was injected intravenously. Blood was sampled from the left brachial artery to measure radioactivity with a scintillation counter 10 minutes after initiation of tracer injection. Scanning was initiated 25 minutes after injection of ${ }^{123}$ I-IMP, and continued for 30 minutes. A Butterworth filter of order 4, with a ramp and a cutoff frequency of 2.2 cycle $\cdot \mathrm{cm}^{-1}$, was used. Scatter correction was not performed, while attenuation correction was performed assuming an elliptical brain outline approximating a circle.

Images reflecting CBF were created by the SPECT autoradiographic method (7). CBF images in $128 \times 128$ mode were obtained to represent six slices of brain parallel to the orbitomeatal plane (OM); $(\mathrm{OM}+20, \mathrm{OM}+30, \mathrm{OM}+40, \mathrm{OM}+50$, $\mathrm{OM}+65$, and $\mathrm{OM}+80 \mathrm{~mm})$. Placement of circular regions of 
interest (ROI) was performed as described in previous studies (8-10). One ROI, $22 \mathrm{~mm}$ in diameter was placed in each cerebellar hemisphere, while $66 \mathrm{ROI}$ approximately $13 \mathrm{~mm}$ in diameter were placed in cerebral cortical and subcortical areas (Fig. 1). Mean rCBF values in frontal, temporal, parietal, and

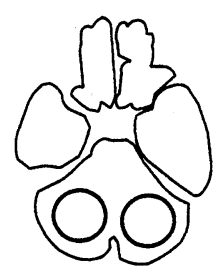

$\mathrm{OM}+20 \mathrm{~mm}$

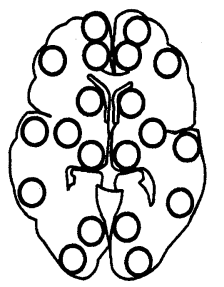

$\mathrm{OM}+50 \mathrm{~mm}$

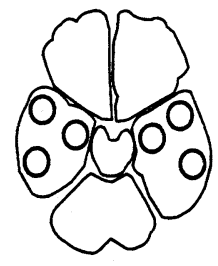

$\mathrm{OM}+30 \mathrm{~mm}$

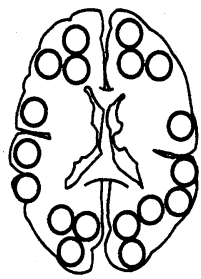

$\mathrm{OM}+65 \mathrm{~mm}$
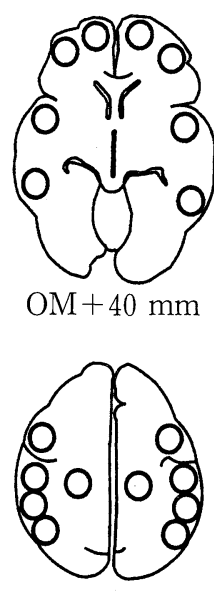

$\mathrm{OM}+80 \mathrm{~mm}$
Figure 1. Circular regions of interest (ROI) $13 \mathrm{~mm}$ and $22 \mathrm{~mm}$ in diameter are depicted in cerebrum and cerebellum, respectively. occipital cortex, deep white matter, thalamus, striatum, and cerebellar hemispheres were obtained in each recipient and normal subject.

\section{Statistical methods}

In each region, $\mathrm{rCBF}$ was compared by the unpaired $t$ test with Bonferoni correction between recipients and normal subjects. The significance threshold was set at $P=0.05$. Additionally, in recipients, Spearman rank correlation coefficients were calculated between overall mean cortical CBF and each of two variables; the interval from transplantation to $\mathrm{CBF}$ measurement, period of hemodialysis before transplantation, blood pressure, hematocrit, and serum creatinine concentration. CyA trough concentrations were monitored in whole blood, allowing for analysis of the correlation between CyA trough concentrations and overall mean cortical rCBF using Spearman rank correlation coefficients. Furthermore, we also analyzed the correlation between CyA trough levels and rCBF in frontal, temporal, parietal, and occipital cortices, deep white matter, thalamus, striatum, and cerebellar hemispheres, respectively, using Spearman rank correlation coefficients.

\section{Results}

Values for rCBF in frontal, temporal, parietal, and occipital cortices, deep white matter, thalamus, striatum, and cerebellar hemispheres in renal transplant recipients were significantly

Normal subjects $\quad$ Recipients

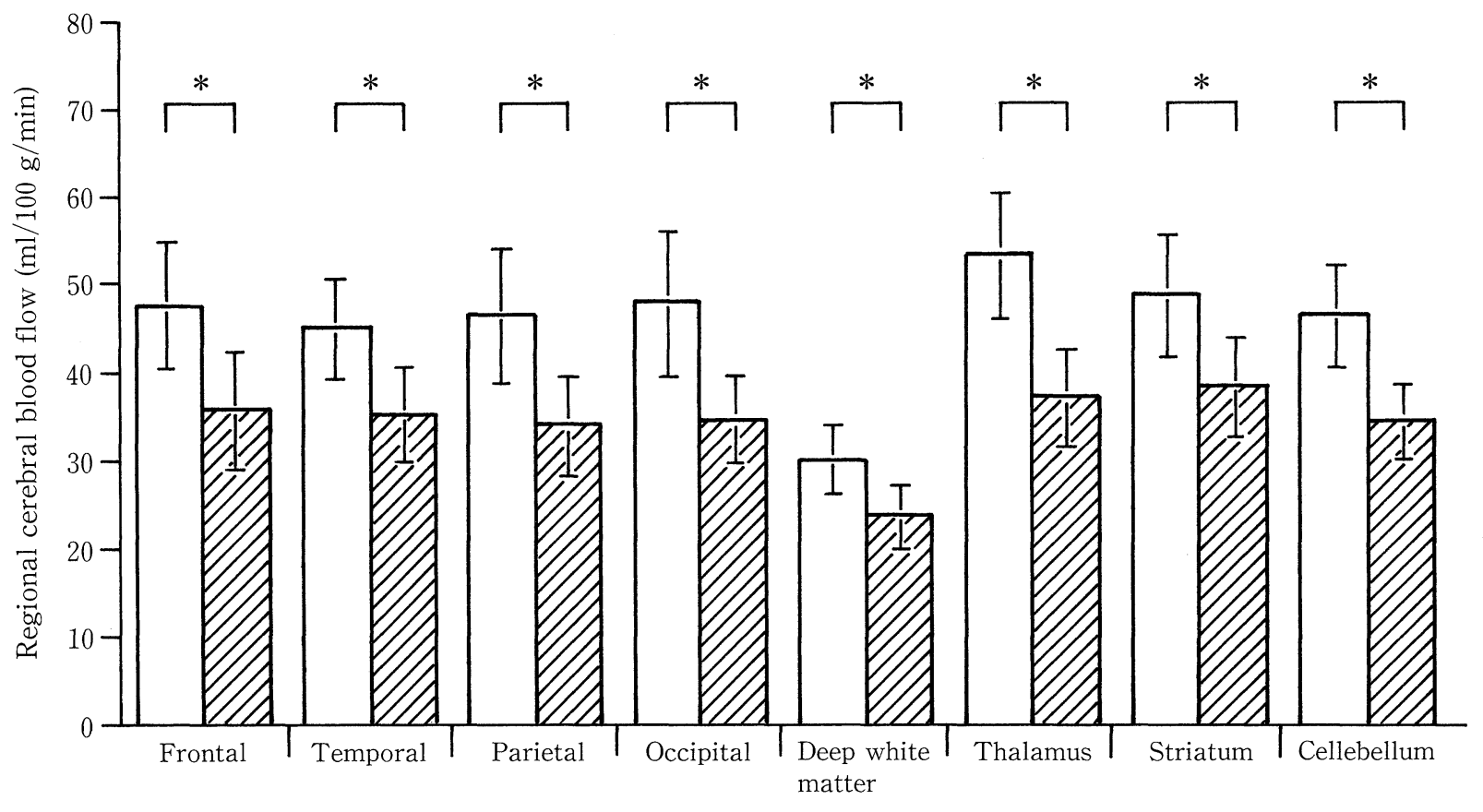

Figure 2. rCBF in normal subjects and renal transplant recipients. Each bar represents the mean \pm SD of rCBF. Each $\mathrm{rCBF}$ in renal transplant recipients is significantly lower than in normal subjects. $(* P<0.001$, the paired-t test with Bonferoni correction). 


\section{Renal transplant recipient}
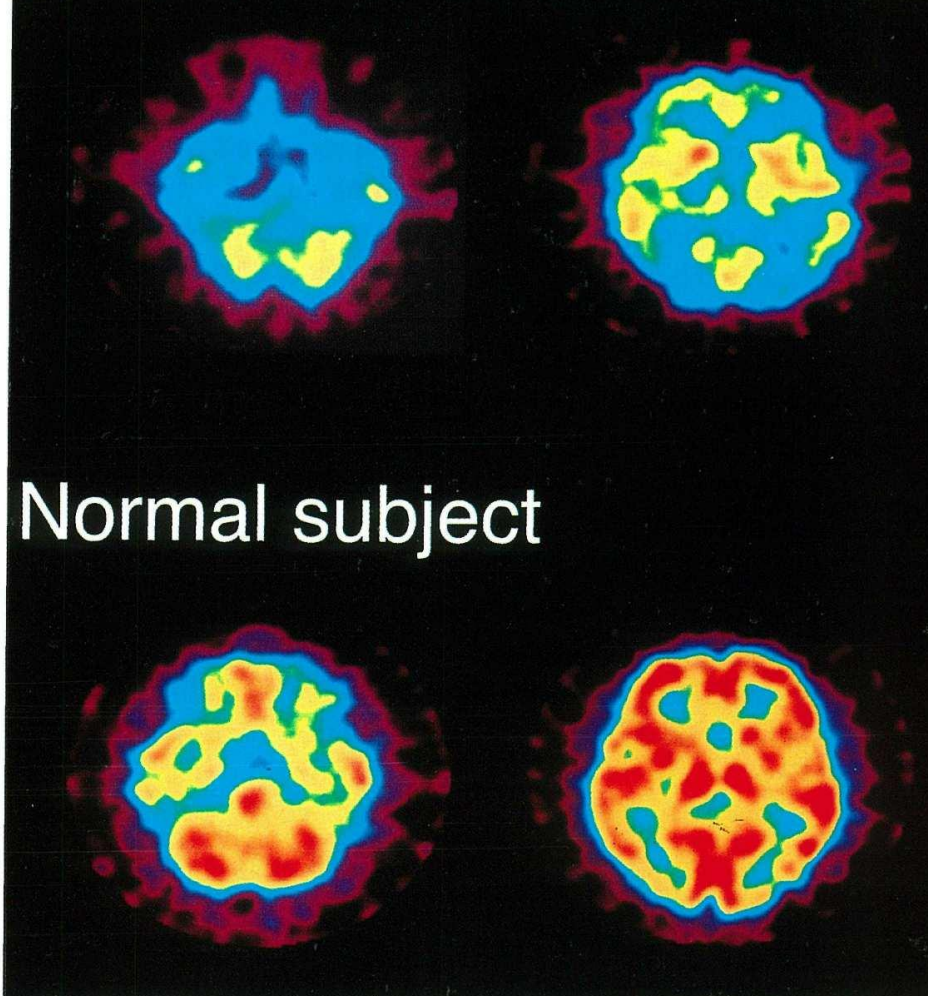

Figure 3. CBF images of a 51-year-old renal transplant recipient and a 60-year-old normal subject $(\mathrm{L}=$ left side).

lower than in normal subjects $(P<0.001)$ (Fig. 2). In transplant recipients, mean $\mathrm{CBF}$ in the frontal cortex was reduced to $74.9 \%$ of normal; $77.8 \%$, in the temporal cortex; $73.1 \%$, in the parietal cortex; $72.2 \%$, in the occipital cortex; $78.6 \%$, in the deep white matter; $69.8 \%$, in the thalamus; $78.6 \%$, in the striatum; and $74.3 \%$, in the cerebellum. CBF images also revealed reduction of each $\mathrm{rCBF}$ in renal transplant recipients compared with normal subjects (Fig. 3).

No significant correlation was noted between the interval from transplantation to CBF measurement, period of hemodialysis before transplantation, systolic blood pressure, diastolic blood pressure, value of hematocrit, or serum creatinine concentration and mean overall cortical $\mathrm{CBF}$ in renal transplant recipients. There was also no significant correlation between overall mean cortical rCBF and CyA trough levels. Figure 4 illustrates CyA trough levels vs overall cortical CBF. There was no significant correlation between CyA trough levels and each rCBF in frontal, temporal, parietal, and occipital cortices, deep white matter, thalamus, striatum, and cerebellar hemispheres in renal transplant recipients.

\section{Discussion}

We studied rCBF in renal transplant recipients and normal

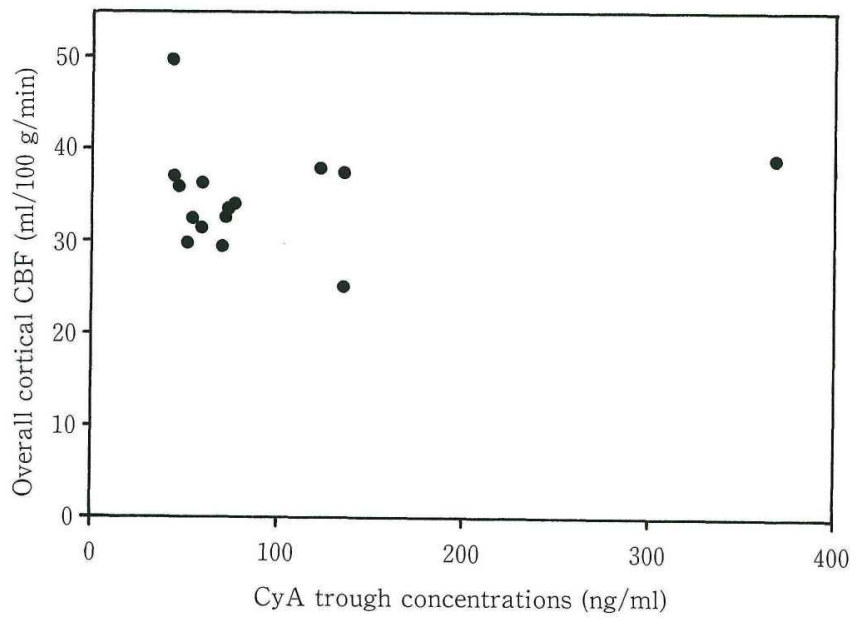

Figure 4. Scatter plot of CyA trough levels to overall mean cortical $\mathrm{rCBF}$. There was no significant correlation between the overall mean cortical rCBF and CyA trough levels using Spearman rank correlation coefficients. 
subjects using SPECT, and demonstrated findings of significantly lower $\mathrm{CCBF}$ in all brain regions in renal transplant recipients, when compared to normal subjects. The reasons for this in CBF reduction are not immediately clear; however, we sought to discuss potential mechanisms causing the reduction of $\mathrm{CBF}$ in renal transplant recipients.

As no significant correlation was found between transplant recipients serum creatinine levels and $\mathrm{CBF}$, the decreased $\mathrm{CBF}$ in renal transplant recipients was not the result of a deterioration in renal function. Moreover, the causative factor was not related to the post transplantation interval, which showed no correlation with CBF. PET study demonstrated that long-term $\mathrm{HD}$ is one of the factors for decreased CBF (11). However, there was no correlation between the overall mean CBF and the period of hemodialysis before transplantation in the present study. Because of a short period of hemodialysis before transplantation, the HD duration may not influence CBF. In spite of a short HD duration, $\mathrm{CBF}$ was significantly decreased in renal transplant recipients compared with normal subjects.

Fourteen renal transplant recipients had hypertension and were maintained on oral antihypertensive agents with good control. It is known that chronic hypertension shifts both the lower and upper limits of autoregulation towards higher pressures (12-15) and this hypertensive adaptation of CBF autoregulation is reversible with chronic hypertensive agents (16, 17). Therefore, an influence of the antihypertensive treatment on $\mathrm{CBF}$ was ruled out.

All of the renal transplant recipients in the present study received prednisolone and cyclosporin $\mathrm{A}(\mathrm{CyA})$. CyA is widely used, as a powerful immunosuppressive agent to enhace the long-term survival of engrafted tissue $(18,19)$. However, CyA is reported to influence organ blood flow in experimental animals. Intracoronary injection of $\mathrm{CyA}$ decreases coronary arterial blood flow in dogs (20), and hepatic blood flow in pigs is decreased significantly by intravenous CyA infusion (21). CyA reduces renal blood flow in rats (22). Thus, administration of CyA can reduce blood flow in a variety of host organs. However, no significant correlation was found between the CyA trough concentrations and mean cortical rCBF. Unfortunately we did not measure the CyA concentration during SPECT scan; instead, we monitored CyA trough concentrations as is conventional to ensure maintenance of engrafted tissue. Therefore, CyA still remains as a potential cause of reduced CBF in renal transplant patients.

It is known that CyA reduces deformability of erythrocytes and induces endothelial-dependent vasoconstriction. Microcirculation is greatly affected by deformability of erythrocytes, and deformability of erythrocytes is a major determinant of resistance to flow, In vivo experiments with erythrocytes demonstrated that CyA causes a reduction in deformability of erythrocytes in association with an influx of calcium (23). Previous studies demonstrated that the reduction in deformability of erythrocytes can be induced merely by elevating intracellular calcium $(24,25)$. Clinical studies also demonstrated a higher erythrocyte calcium content in patients receiving CyA, when compared to healthy control subjects (26); furthermore, eryth- rocyte deformability is reduced in transplant recipients treated with CyA (27). Taken together, CyA is thought to influence erythrocytic rheologic properties, especially deformability, by increasing the intracellular calcium ion concentration. Administration of CyA also is reported to induce endothelial-dependent vasoconstriction (28). Exposure of cultured human endothelial cells to CyA has been reported to induce production and secretion of endothelin-1 (ET-1) (29-31), which has strong vasoconstrictive effects. Systemic infusion of a high concentration of CyA in animals results in marked elevation of ET-1 (32). Moreover, recipients treated orally with CyA have higher plasma ET-1 concentrations than untreated individuals (33). Experimentally, a similar increase in plasma ET-1 is caused not by activation of the endothelin-converting enzyme-1 gene but by increased prepro-ET-1 (pp-ET-1) mRNA expression, following intrarenal CyA injection (34). ET-1 injected directly into the cerebral circulation causes a reduction in CBF (35). Therefore, one possible reason for CyA-associated decreases in CBF is elevation of plasma ET-1. Thus, we must suspect an influence of CyA on CBF (caused by a CyA-induced decrease in deformability of erythrocytes, an increase in endothelialdependent vasoconstriction, or both) in renal transplant patients.

We described above the influence of CyA on rheology. In the aspect of its influence on neuronal metabolism, $\mathrm{CyA}$ is known to induce neurotoxicity (36). A reversible posterior leukoencephalopathy syndrome is the most serious complication of CyA. Symptoms of reversible posterior leukoencephalopathy are characterized by headache, altered mental functioning, seizures, cortical blindness, and other visual disturbances, with associated hypertension. CT nonenhancing areas of hypodensity are seen predominantly in the white matter of the occipital regions and MRI analysis demonstrates decreased signals on T1weighted images, and hyperintense signals on T2-weighted images, in the occipital regions of patients with reversible posterior leukoencephalopathy. In the present renal transplant recipients, there was no significant correlation between CyA trough levels and rCBF in all of the investigated regions. However, it is known that neurotoxicity due to CyA can occur at normal and at high drug levels (36). Therefore, the influence of subclinical CyA neurotoxicity on CBF can not be denied because of the coupling of CBF to cerebral metabolism, although there were no symptoms, or neuroimaging findings, of reversible posterior leukoencephalopathy syndrome in the present recipients.

The presence of atherosclerosis may influence CBF in renal transplant recipients. There was a possibility of atherosclerosis in renal transplant recipients due to a variety of causes, though we did not examine the ocular fundus which would have allowed us to determine the degree of arteriosclerosis. All of the renal transplant recipients in the present study received prednisolone as well as CyA. Prednisolone induces proliferation of aortic smooth muscle cells and atherosclerosis in a gradual manner $(37,38)$. Administration of CyA has been reported to cause calcification in some tissues $(39,40)$. Canavese et al also reported a patient with worsening vascular calcifications following renal transplantation although the im- 
munosuppressive regimen was not described (41). Moreover, Hofbauer et al provided a potential mechanism for CyA-induced bone loss, and the propensity of CyA to cause vascular disease (42). The hypothesis of Lindner et al of an accelerated atherosclerosis in chronic dialysis patients has been widely accepted (43). Risk factors for atherogenesis in chronically uremic patients are thought to be tensile stress, shear stress, alterations in blood flow, disturbance of lipid metabolism, disturbance of glucose metabolism, hyperhomocysteinemia, disturbance of calcium and phosphorus metabolism, cytokines, and vasoactive, endothelium-, and platelet-derived compounds (44). The increase of homocystein concentrations generally persists after successful renal transplantation (45). This implies that atherosclerosis may progress even after renal transplantation. Taken together, atherosclerosis may be brought about by various causes in renal transplant recipients. The present result can not completely deny the influence of atherosclerosis on $\mathrm{CBF}$ in renal transplant recipients, although no significant correlation was noted between the interval from transplantation to CBF measurement, or the period of hemodialysis before transplantation and mean overall cortical CBF in renal transplant recipients.

\section{Conclusion}

The present study revealed no significant correlation between cortical CBF and the duration of the interval from transplantation to measurement of $\mathrm{CBF}$ in renal transplant recipients. However, cerebral circulatory status is thought to represent continuous hypoperfusion in transplant recipients. We know of no reports of cerebral infarction following chronic cerebral hypoperfusion in transplant recipients. Therefore, follow-up MRI or CT may be necessary to detect occurrence of ischemic lesions in renal transplant recipients.

Acknowledgements: We thank Dr. Parsia A. Vagefi for his critical reading of the manuscript.

\section{References}

1) Hohage H, Arlt M, Bruckner D, Dietl KH, Zidek W, Spieker C. Effects of cyclosporin A and FK 506 on lipid metabolism and fibrinogen in kidney transplant recipients. Clinical Transplantation 11: 225-230, 1997.

2) Vorstrup $S$, Lass $P$, Waldemar G, et al. Increased cerebral blood flow in anemic patients on long-term hemodialytic treatment. J Cereb Blood Flow Metab 12: 745-749, 1992.

3) Gottlieb D, Mildworf B, Rubinger D, Melamed E. The regional cerebral blood flow in patients under chronic hemodialytic treatment. J Cereb Blood Flow 7: 659-661, 1987.

4) Johnson WJ, McCarthy JT, Yanagihara T, et al. Effects of recombinant human erythropoietin on cerebral and cutaneous blood flow and on blood coagulability. Kidney Int 38: 919-924,1990.

5) Metry G, Wikström B, Valind S, et al. Effect of normalization of hematocrit on brain circulation and metabolism in hemodialysis patients. J Am Soc Nephrol 10: 854-863, 1999.

6) Driessen GK, Haest CW, Heidtmann H, Kamp D, Schmid-Schonbein H. Effect of reduced red cell "deformability" on flow velocity in capillaries of rat mesentery. Pflugers Arch 388: 75-78, 1980.

7) Iida $\mathrm{H}$, Itoh $\mathrm{H}$, Nakazawa $\mathrm{M}$, et al. Quantitative mapping of regional cerebral blood flow using Iodine-123-IMP and SPECT. J Nucl Med 35: 2019-2030, 1994.

8) Komaba Y, Nomoto T, Kitamura S, Terashi A. Cavernous angioma with olivary hypertrophy and contralateral cerebellar diaschisis. Intern Med 36: 504-507, 1997.

9) Komaba Y, Kitamura S, Terashi A. Effect of prostaglandin $E_{1}$ on cerebral blood flow in patients with chronic cerebral infarction. Intern Med 37: 841-846, 1998.

10) Komaba Y, Osono E, Kitamura S, Katayama Y. Crossed cerebellocerebral diaschisis in patients with cerebellar stroke. Acta Neurol Scand 101: 8$12,2000$.

11) Kanai $H$, Hirakata $H$, Nakane $H$, et al. Depressed cerebral oxygen metabolism in patients with chronic renal failure: a positron emission tomography study. Am J Kidney Dis 38: S129-133, 2001.

12) Strandgaard S, Jones JV, MacKenzie ET, Harper AM. Upper limit of cerebral blood flow autoregulation in experimental renovascular hypertension in the baboon. Circ Res 37: 164-167, 1975.

13) Strandgaard S. Autoregulation of cerebral blood flow in hypertensive patients. The modifying influence of prolonged antihypertensive treatment on the tolerance to acute, drug-induced hypotension. Circulation 53: 720-727, 1976.

14) Barry DI, Strandgaard S, Graham DI, et al. Cerebral blood flow in rats with renal and spontaneous hypertension: resetting of the lower limit of autoregulation. J Cereb Blood Flow Metab 2: 347-353, 1982.

15) Harper SL, Bohlen HG. Microvascular adaptation in the cerebral cortex of adult spontaneously hypertensive rats. Hypertension 6: 408-419, 1984.

16) Vorstrup S, Barry DI, Jarden JO, et al. Chronic antihypertensive treatment in the rat reverses hypertension-induced changes in cerebral blood flow autoregulation. Stroke 15: 312-318, 1984.

17) Muller F, Lartaud I, Bray L, et al. Chronic treatment with the angiotensin I converting enzyme inhibitor, perindopril, restores the lower limit of autoregulation of cerebral blood flow in the awake renovascular hypertensive rat. J Hypertens 8: 1037-1042, 1990.

18) Christians U, Sewing KF. Cyclosporin metabolism in transplant patients. Pharmac Ther 57: 291-345, 1993.

19) Cohen DJ, Loertscher R, Rubin MF, Tilney NL, Carpenter CB, Strom TB. Cyclosporine: a new immunosuppressive agent for organ transplantation. Ann Intern Med 101: 667-682, 1984.

20) Khalil A, Carrier M, Latour JG, Pelletier LC. Cyclosporine A decreases coronary blood flow in dogs. Ann Chir 49: 689-693, 1995.

21) Andreoni KA, O'Donnell CP, Burdick JF, Robotham JL. Hepatic and renal blood flow responses to a clinical dose of intravenous cyclosporine in the pig. Immunopharmacology 28: 87-94, 1994.

22) Sandberg JO, Groth CG, Andersson A, Jansson L. Acute effects of different immunosuppressive drugs on pancreatic, islet, renal, and arterial hepatic blood flow in anesthetized rats. Transpl Int 7: 319-323, 1994.

23) Baskurt OK, Senturk UK, Dayan N, et al. Cyclosporin A affects red blood cell deformability in vivo but not in vitro in guinea pig. J Pharmacol Exp Ther 274: 1438-1442, 1995.

24) Tanaka T, Kadowaki K, Lazarides E, Sobue $\mathrm{K}$. $\mathrm{Ca}^{2+}$-dependent regulation of the spectrin/actin interaction by calmodulin and protein 4.1. J Biol Chem 266: 1134-1140, 1991.

25) Friederichs E, Meiselman HJ. Effects of calcium permeabilization on RBC rheologic behavior. Biorheology 31: 207-215, 1994.

26) Babarykin D, Amerika D, Adamsone I, Valinietse M, Rosental R. Effect of Sandimmun Neoral on the level of bivalent cations in erythrocytes of kidney transplant recipients. Ann Transplant 1: 23-26, 1996.

27) Schut NH, Bilo HJ, Popp-Snijders C, Goedhart PT, Wilmink JM. Erythrocyte deformability, endothelin levels, and renal function in cyclosporintreated renal transplant recipients: effects of intervention with fish oil and corn oil. Scand J Clin Lab Invest 53: 499-506, 1993.

28) Auch-Schwelk W, Bossaller C, Götze S, Thelen J, Fleck E. Endothelial and vascular smooth muscle function after chronic treatment with cyclosporin A. J Cardiovasc Pharmacol 21: 435-440, 1993.

29) Bunchman TE, Brookshire CA. Cyclosporine-induced synthesis of endotheline by cultured human endothelial cells. J Clin Invest 88: 310$314,1991$. 


\section{CBF in Renal Transplant Recipients}

30) Nakahama H. Stimulatory effect of cyclosporine A on endothelin secretion by a cultured renal epithelial cell line, LLC-PK1. Eur J Pharmacol 180: 191-192, 1990.

31) Nakahama H, Fukunaga M, Kakihara M, et al. Comparative effects of cyclosporine and FK-506 on endothelin secretion by a cultured renal cell line, LLC-PK1. J Cardiovasc Pharmacol 17 Suppl 7: S172- S173, 1991.

32) Kon V, Sugiura M, Inagami T, Harvie BR, Ichikawa I, Hoover RL. Role of endotherin in cyclosporine-induced glomerular dysfunction. Kidney Int 37: 1487-1491, 1990.

33) Grieff M, Loertscher R, Shohaib SA, Stewart DJ. Cyclosporine-induced elevation in circulating endothelin- 1 in patients with solid-organ transplants. Transplantation 56: 880-884, 1993.

34) Nakayama $Y$, Nonoguchi $H$, Kiyama $S$, et al. Intranephron distribution and regulation of endothelin-converting enzyme-1 in cyclosporin A-induced acute renal failure in rats. J Am Soc Nephrol 10: 562-571, 1999.

35) Salom JB, Torregrosa G, Miranda FJ, Alabadí JA, Alvarez C, Alborch E. Effects of endothelin-1 on the cerebrovascular bed of the goat. Eur $\mathbf{J}$ Pharmacol 192: 39-45, 1991.

36) Gijtenbeek JM, van den Bent MJ, Vecht CJ. Cyclosporine neurotoxicity: a review. J Neurol 246: 339-346, 1999.

37) Hauss WH, Mey J, Schulte H. Effect of risk factors and antirheumatic drugs on the proliferation of aortic wall cells. Atherosclerosis 34: 119$143,1979$.
38) Lee WM, Morrison ES, Scott RF, Lee KT, Kroms M. Effects of methyl prednisolone and colchicine on the development of atherosclerosis in swine. Atherosclerosis 25: 213-224, 1976.

39) Kubota RT. Resnik CS. Periarticular calcification in immunosuppressed cardiac transplant patients. Invest Radiol 23: 113-117, 1988.

40) Richter-Reichhelm HB, Schulte AE. Results of a cyclosporin A ringstudy. Toxicology 128: 91-94, 1998.

41) Canavese C, Cesarani F, Stratta C, et al. Dramatic worsening of vascular calcifications after kidney transplantation in spite of early parathyroidectomy. Clin Nephrol 54: 487-491, 2000.

42) Hofbauer LC, Shui C, Riggs BL, et al. Effects of immunosuppressants on receptor activator of NF-kappaB ligand and osteoprotegerin production by human osteoblastic and coronary artery smooth muscle cells. Biochem Biophys Res Commun 280: 334-339, 2001.

43) Lindner A, Charra B, Sherrard DJ, Scribner BH. Accelerated atherosclerosis in prolonged maintenance hemodialysis. N Engl J Med 28: 290: 697-701, 1974.

44) London GM, Drueke TB. Atherosclerosis and arteriosclerosis in chronic renal failure. Kidney Int 51: 1678-1695, 1997 (editorial).

45) Massy ZA, Chadefaux-Vekemans B, Chevalier A, et al. Hyperhomocysteinaemia: a significant risk factor for cardiovascular disease in renal transplant recipients. Nephrol Dial Transplant 9: 1103-8, 1994. 